Bond University

Research Repository

\title{
Fish and omega-3 intake and health in older people
}

Marshall, Skye; Van der Meij, Barbara S

Published in:

Maturitas

DOI:

10.1016/j.maturitas.2018.04.002

Licence:

CC BY-NC-ND

Link to output in Bond University research repository.

Recommended citation(APA):

Marshall, S., \& Van der Meij, B. S. (2018). Fish and omega-3 intake and health in older people. Maturitas, 115, 117-118. https://doi.org/10.1016/j.maturitas.2018.04.002

\section{General rights}

Copyright and moral rights for the publications made accessible in the public portal are retained by the authors and/or other copyright owners and it is a condition of accessing publications that users recognise and abide by the legal requirements associated with these rights.

For more information, or if you believe that this document breaches copyright, please contact the Bond University research repository coordinator. 


\section{Accepted Manuscript}

Title: Fish and omega-3 intake and health in older people

Author: Skye Marshall

PII:

DOI:

S0378-5122(18)30223-8

Reference: $\quad$ MAT 6989 https://doi.org/10.1016/j.maturitas.2018.04.002

To appear in: $\quad$ Maturitas

Author: Barbara van der Meij

PII: S0378-5122(18)30223-8

DOI: https://doi.org/10.1016/j.maturitas.2018.04.002

Reference: MAT 6989

To appear in: $\quad$ Maturitas

Received date: $\quad 29-3-2018$

Please cite this article as: van der Meij Barbara.Fish and omega-3 intake and health in older people.Maturitas https://doi.org/10.1016/j.maturitas.2018.04.002

This is a PDF file of an unedited manuscript that has been accepted for publication. As a service to our customers we are providing this early version of the manuscript. The manuscript will undergo copyediting, typesetting, and review of the resulting proof before it is published in its final form. Please note that during the production process errors may be discovered which could affect the content, and all legal disclaimers that apply to the journal pertain. 


\section{Fish and omega-3 intake and health in older people}

\section{Dr Skye Marshall ${ }^{1,2}$, Dr Barbara van der Meij ${ }^{3,4}$}

1. Postdoctoral Research Fellow, Bond University, Gold Coast, Queensland, Australia.

2. Corresponding author: Bond Institute of Health and Sport, 2 Promethean Way, Robina, Queensland, 4226, Australia. skye_marshall@bond.edu.au

3. Conjoint Senior Research Dietitian, Bond University, Gold Coast, Queensland, Australia.

4. Conjoint Senior Research Dietitian, Mater Group, Brisbane, Queensland, Australia.

Corresponding author: Skye Marshall, Bond University, Bond Institute of Health \& Sport, 2 Promethean Way, Australia.

Journal: Maturitas

Paper type: Editorial.

Keywords: fish; omega-3; cardiovascular disease; longevity; cognitive decline

Epidemiological studies have linked fish consumption with increased longevity and improvements in age-related conditions such as cognitive decline and cardiovascular disease (CVD) [1-3]. Fish is a rich source of eicosapentaenoic acid (EPA) and docosahexanoic acid (DHA), marine-derived omega-3 polyunsaturated fatty acids (PUFAs) which are the suggested mediator of such health benefits. However, fish is also a source of other nutrients which are important for healthy ageing such as protein, calcium, iron and vitamin E and D. Whether benefits of omega-3 PUFAs can be obtained via supplementation as opposed to consuming fish as part of the usual diet is still not fully understood. Further, whether these health benefits are obtained when high intakes of fish and/or supplements commenced in older adulthood as opposed to over the lifespan is also of interest. In the past 12-months, several large and high-quality studies on this topic have been published. 
The suggested pathway for fish to improve cognition is related to DHA. DHA forms part of the structure of the human brain, particularly the hippocampus, thereby contributing to episodic memory and cognition, as well as providing multiple neuroprotective mechanisms to prevent Alzheimer's disease. When pooling outcomes from observational studies in 23,688 older adults (72 - 82 years), with $4-9$ years follow-up, those who consumed four or more serves of fish a week compared to those who consumed less than one serve had a significantly slowed rate of decline in episodic memory $(\beta=0.018$ standard units/year [95\%CI: 0.004-0.032]; $\mathrm{P}=0.024$ ) [1]. This can be translated into having an episodic memory equal to those four years younger [1].

Three randomized controlled trials supplementing doses of less than 2.0g of omega-3 PUFAs in healthy older adults and those with some cognitive impairment, for either several months up to 5-years, showed no effect on cognition $[4,5]$. However, two RCTs which used doses of $2.2 \mathrm{~g}$ and $2.4 \mathrm{~g}$ in healthy older adults and those with cognitive decline, respectively, showed mild improvements in memory after only 6-months [4]. However, no evidence yet supports omega-3 PUFA supplementation in older adults for the prevention and treatment of Alzheimer's disease [4].

This conflicting evidence may be partly explained by the differences in the duration of fish intake and omega-3 PUFA supplementation. Participants in the observational studies [1] are likely to have maintained their dietary patterns over decades, and therefore the beneficial effects on episodic memory may be the result of long-term high fish intake. Although there is some evidence of effect with the use of omega-3 PUFA doses over $2.0 \mathrm{~g}$ per day, the lack of large effects may be due to the shorter duration of intake (i.e. months or years as opposed to decades). Additionally, these new studies suggest fish consumed as a food may be more beneficial than omega-3 PUFA supplementation for preservation of cognition, although this is not yet clear due to the differences in duration of fish versus supplement consumption in available studies. Overall, current evidence indicates that older adults with a high fish intake should be encouraged to continue this behavior, whereas supplementing omega-3 PUFAs later in life to prevent and/or treat cognitive decline is not currently justified by the evidence.

\section{Prevention and treatment of CVD}

The direct causal relationship between fish consumption and CVD is unclear, although observational evidence suggests there is an inverse relationship. Omega-3 PUFAs may prevent and contribute to the management of CVD via several pathways, including anti- 
inflammatory properties which prevent plaque rupture, and improvement of lipid profiles and blood pressure [3]. A 2018 meta-analysis of 77,917 older adults found that compared to placebo or open-label controls, up to $2 \mathrm{~g}$ doses of EPA and/or DHA, supplemented for at least 12-months, did not significantly improve any pooled outcomes related to cardiovascular disease [2]. In addition to the lack of evidence, cardiovascular guidelines recommend caution with supplementing omega-3 PUFAs to older adults [2]. Further research examining higher doses of omega-3 PUFA supplementation, as well as long-term fish consumption, on the prevention of cardiovascular events is needed. Research agrees with studies examining outcomes in cognition, where high fish intake over a long period of time may be beneficial for cardiovascular outcomes, but supplementation of omega-3 PUFAs in older adults is not yet supported.

\section{Impact on longevity}

Proposed mechanisms of action for the association of high fish consumption and increased longevity are its anti-inflammatory properties as well as the inverse association of omega-3 PUFAs intake and telomere shortening, a process which limits proper cell functioning in ageing [3]. Although epidemiological studies observe increased longevity in societies which have high fish intakes, only animal studies examining omega-3 PUFA supplementation and longevity are available. Although initial mouse studies showed promising results, subsequent and larger studies of diverse mice breeds showed no effect on longevity with low or high dose omega-3 PUFA supplementation. As animal studies do not currently support the role of omega-3 PUFA supplementation to slow ageing, this research is not likely to be translated to human trials, and supplementation cannot be recommended by health professionals for this purpose [3].

\section{Food versus supplements}

Observational research shows older adults with high fish intakes appear to have improved age-related health outcomes, even when controlling for other dietary and lifestyle factors; however, pooled research is consistently indicating that supplementing omega-3 PUFAs is not supported to improve cognition, CVD or longevity in older adults. The most recent evidence keeps our focus on supporting fish consumption in older adults. In addition to possible health benefits, fish as a meal promotes the individual's connection with food, contributing to improved quality of life across cultures. People who choose to eat fish do so for the taste, for the value they find in preparing and cooking the fish, or the cultural and social connection they find in consuming fish-specific dishes, whether it be traditional fish 
and chips, ceviche or fish chowder. Therefore, instead of prescribing omega-3 PUFA supplements, health professionals and aged care homes should make sure to promote fish consumption in older adults where it is desired for overall health and wellbeing.

\section{Contributors}

Skye Marshall drafted the manuscript.

Barbara van der Meij contributed to manuscript revision.

Both authors were responsible for the concept of the editorial and saw approved the final version.

\section{Conflict of interest}

The authors declare they have no actual or potential conflict of interest in relation to this editorial.

\section{Funding}

No funding was received for the preparation of this editorial.

\section{Provenance and peer review}

This article was commissioned and not externally peer reviewed. 


\section{References}

[1] C. Samieri, M.-C. Morris, D.A. Bennett, C. Berr, P. Amouyel, J.-F. Dartigues, C. Tzourio, D.I. Chasman, F. Grodstein, Fish intake, genetic predisposition to alzheimer's disease and decline in global cognition and memory in five cohorts of older persons, Am. J. Epidemiol. (2017).

[2] T. Aung, J. Halsey, D. Kromhout, H.C. Gerstein, R. Marchioli, L. Tavazzi, J.M. Geleijnse, B. Rauch, A. Ness, P. Galan, Associations of Omega-3 Fatty Acid Supplement Use With Cardiovascular Disease Risks: Meta-analysis of 10 Trials Involving 77917 Individuals, JAMA cardiology (2018).

[3] J.P. de Magalhães, M. Müller, G.E. Rainger, W. Steegenga, Fish oil supplements, longevity and aging, Aging 8(8) (2016) 1578.

[4] T. Cederholm, Fish consumption and omega-3 fatty acid supplementation for prevention or treatment of cognitive decline, dementia or Alzheimer's disease in older adults-any news?, Curr. Opin. Clin. Nutr. Metab. Care 20(2) (2017) 104-109.

[5] S. Andrieu, S. Guyonnet, N. Coley, C. Cantet, M. Bonnefoy, S. Bordes, L. Bories, M.-N. Cufi, T. Dantoine, J.-F. Dartigues, Effect of long-term omega 3 polyunsaturated fatty acid supplementation with or without multidomain intervention on cognitive function in elderly adults with memory complaints (MAPT): a randomised, placebo-controlled trial, The Lancet Neurology 16(5) (2017) 377389. 